\title{
Electron Microscopic Study of Rheumatoid Synovial Vasculature Intimate Relationship Between Tall Endothelium and Lymphoid Aggregation
}

\author{
Tetsuhiro Iguchi and Morris Ziff \\ Harold C. Simmons Arthritis Research Center; and Inflammation Research Unit, Department of Internal Medicine, The University of \\ Texas Health Science Center at Dallas, Southwestern Medical School, Dallas, Texas 75235
}

\begin{abstract}
The relationship between (a) "tallness" and (b) cross-sectional area of the endothelial cells (EC) of postcapillary venules (PCV) and capillaries and the cellular composition of adjacent perivascular mononuclear cell infiltrates in rheumatoid (RA) synovial membrane has been examined by electron microscopy. "Tallness" of the EC was measured as the ratio of the height of the EC to its base (H/B). H/B showed a strong positive correlation with the number and percent of perivascular lymphocytes, i.e., the denser the lymphoid aggregation, the taller the EC. In contrast, H/B showed negative correlations with percent perivascular plasma cells, macrophages, and fibroblast(cyte)s. No such correlations were observed with pericapillary infiltrates. A computerbased morphometric technique yielded similar relationships between the cross-sectional area of the EC and the composition of the perivascular infiltrates. These results indicate that the EC of PCV in lymphocyte-rich areas of synovium tend to be tall and to occupy an increased fraction of the cross-sectional area of the vessel. In contrast, in areas rich in macrophages and plasma cells, EC tend to be flat and to occupy a smaller fraction of the cross-sectional area. PCV in uninfiltrated interstitial areas and in normal synovium had flat EC, and capillaries had flat EC regardless of the character of the surrounding infiltrate. Finally, PCV in lymphocyte-rich areas closely resembled those of tonsil in appearance. Our findings indicate that the PCV of the RA synovial membrane from which lymphocytes emigrate to form perivascular lymphoid aggregates resemble those of lymphoid tissue. They suggest that chronic inflammatory tissue and normal lymphoid tissue share mechanisms of lymphocyte emigration.
\end{abstract}

\section{Introduction}

Rheumatoid arthritis (RA) ${ }^{1}$ synovitis is characterized by mononuclear cell infiltration. In the sublining region of the synovium, the mononuclear cells are distributed in a variety of patterns. There are areas of lymphoid aggregation, which have been termed lymphocyte-rich areas $(1,2)$, and areas containing lymphocytes,

Address correspondence and reprint requests to Dr. Ziff, Department of Internal Medicine, University of Texas Health Science Center, 5323 Harry Hines Boulevard, Dallas, TX 75235.

Received for publication 12 September 1985.

1. Abbreviations used in this paper: EC, endothelial cells; EM, electron microscope; $\mathrm{H} / \mathrm{B}$, ratio of the mean height of a vessel's EC to the mean base; IL-1, interleukin 1; o.d., outer diameter, PCV, postcapillary venules; RA, rheumatoid arthritis.

J. Clin. Invest.

(c) The American Society for Clinical Investigation, Inc.

0021-9738/86/02/0355/07 \$1.00

Volume 77, February 1986, 355-361 macrophages, and plasma cells. Because the latter areas are often located at the margin of lymphocyte-rich areas and contain many blastic cells, these areas have been termed transitional areas. Finally, there are areas rich in plasma cells, presumably as a result of extensive $B$ cell proliferation and differentiation. On the basis of monoclonal antibody staining, it has been found (38) that the lymphocyte-rich areas are made up predominantly of helper, inducer $T$ cells while the transitional areas contain increased percentages of suppressor cytotoxic $T$ cells (8).

The RA synovial membrane shares a number of properties, both structural and functional, with lymphoid tissue. The lymphocyte-rich areas resemble the paracortical areas of the lymph node in their dense concentrations predominantly of helper $\mathrm{T}$ cells (9-11). Occasionally, germinal centers rich in B cells are seen (6). Similar amounts of immunoglobulin are synthesized by the two types of tissue, and the relative proportions of the immunoglobulin classes that are synthesized are also similar (12).

In lymphoid tissue, lymphocytes emigrate from the blood into the paracortical region through postcapillary venules lined with tall endothelial cells (EC) (13-16). Recent evidence indicates that vessels resembling tall endothelial venules exist in the RA synovial membrane as well as in the synovial membranes of a number of other arthropathies (17-19), and that the EC in these tissues tend to be tall in areas where lymphocytes are aggregated (17). In the present report, the relationship between the tallness of the endothelium and the composition of the perivascular infiltrates in the RA synovium has been investigated in detail using an electron microscopic technique. It has been observed that the "tallness" of the endothelium in postcapillary venules is closely related to the concentration of lymphocytes in the perivascular infiltrate.

\section{Methods}

Tissues. 20 synovial membrane samples from patients with classical or definite RA were obtained at synovectomy or reconstructive joint surgery. We also examined three normal synovial membranes from patients with intraarticular ligamentous injury, and three tonsils obtained at tonsillectomy.

Synovial specimens were minced into $1-\mathrm{mm}^{3}$ pieces and fixed with 2.5\% glutaraldehyde (Sigma Chemical Co., St. Louis, MO). Tonsils were fixed with Carson's fixative (20). Specimens were washed with $0.1 \mathrm{M}$ phosphate buffer (pH 7.4), postfixed with $1 \%$ osmium tetroxide (Ladd Research Industries, Inc., Burlington, VT), washed, and dehydrated in graded alcohol to $100 \%$ and immersed in propylene oxide (J. T. Baker Chemical Co., Phillipsburg, NJ) for $20 \mathrm{~min}$. Specimens were then transferred into Epon 812 (Electron Microscopy Sciences, Ft. Washington, PA) diluted with propylene oxide, embedded in pure Epon, and polymerized.

Light and electron microscopy. Semi-thin sections, $\sim 1 \mu \mathrm{m}$ thick, were made from three to four blocks prepared from each tissue specimen, and stained with $1 \%$ Toluidine Blue in borax. Vessels, appearing to be either venules or capillaries under the light microscope, were chosen for further study in the electron microscope (EM). Selected areas were 


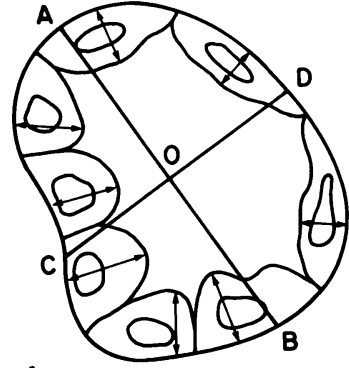

A

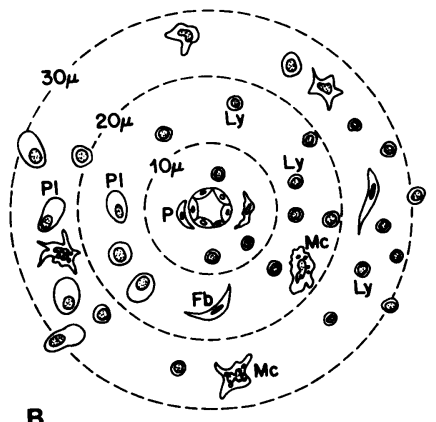

Figure $1(A)$ Measurement of o.d. of vessels and $\mathrm{H} / \mathrm{B}$ of $\mathrm{EC}$. $A B$ indicates the longest o.d. of the vessel, and $C D$, drawn perpendicular to $A B$ through the center of $A B$, represents the short o.d. Mean o.d. was calculated as the average of $A B$ and $C D$. Mean height of the EC was measured as indicated by the arrows. Mean base of the EC was calculated from the circumference of the vessel, measured by planimetry, divided by the number of EC. (B) Measurement of number and percent of mononuclear cell types within a $30-\mu \mathrm{m}$ perimeter of a vessel. Cells were classified as lymphocytes $(L y)$, macrophages $(M c)$, plasma cells $(P l)$, fibroblasts $(F b)$ (or fibrocytes), pericytes $(P)$, and miscellaneous cells, and were counted. Percentages of each type were calculated.

trimmed and ultrathin sections were made on an LKB Ultratome (LKB Instruments, Inc., Gaithersburg, MD) using a diamond knife. Sections were then picked upon a Formvar-coated (Ladd Research Industries),

copper-rhodium plated 100 mesh (Ernest F. Fullam, Inc., Schenectady, NY) and stained with uranyl acetate and lead citrate. Photos in magnifications ranging from $\times 560$ to $\times 6,800$ (original magnification) were taken with an electron microscope (301; Philips Electronic Instruments, Inc., Mahwah, NJ).

On the basis of their appearance in the EM, and utilizing structural criteria (21-24), small arteries and arterioles were excluded. Vessels in which the quotient of the long outer diameter (o.d.) divided by the short o.d. was over 3.0 (Fig. $1 \mathrm{~A}$ ) were also excluded because of the possibility that these vessels might have been sectioned obliquely.

Measurement of vessels. To document the size of vessels, the mean of the long and short o.d., measured from the bases of the EC on opposite sides of the vessel, was calculated. The short o.d. was established by drawing a perpendicular through the center of the long o.d. On the basis of measurements in rabbit skin, Rhodin (22) has described capillaries as having a luminal diameter up to $8 \mu \mathrm{m}$, which would correspond to an o.d. of $\sim 10 \mu \mathrm{m}$ after correcting for EC height. However, in the RA synovial membrane, vessels with a mean o.d. between 10 and $15 \mu \mathrm{m}$ often had the appearance of capillaries, i.e., they had three or less EC in a cross-sectional area and prominent pericytes $(23,24)$. Accordingly, vessels with a mean o.d. of $\langle 15 \mu \mathrm{m}$ were classified as capillaries.

Vessels encountered in this study with mean o.d. between 15.2 and $50.6 \mu \mathrm{m}$ were classified as postcapillary venules since vessels in this size range frequently had tall endothelium. Vessels of larger size were not examined because of the difficulty of including larger vessels together with their perivascular infiltrates in a single electron photomicrograph of appropriate magnification.

In vessels selected for detailed examination, the mean o.d., circumference, and the number and height of the $\mathrm{EC}$ were measured. The tallness of the EC was quantitated by measurement of the ratio of the mean

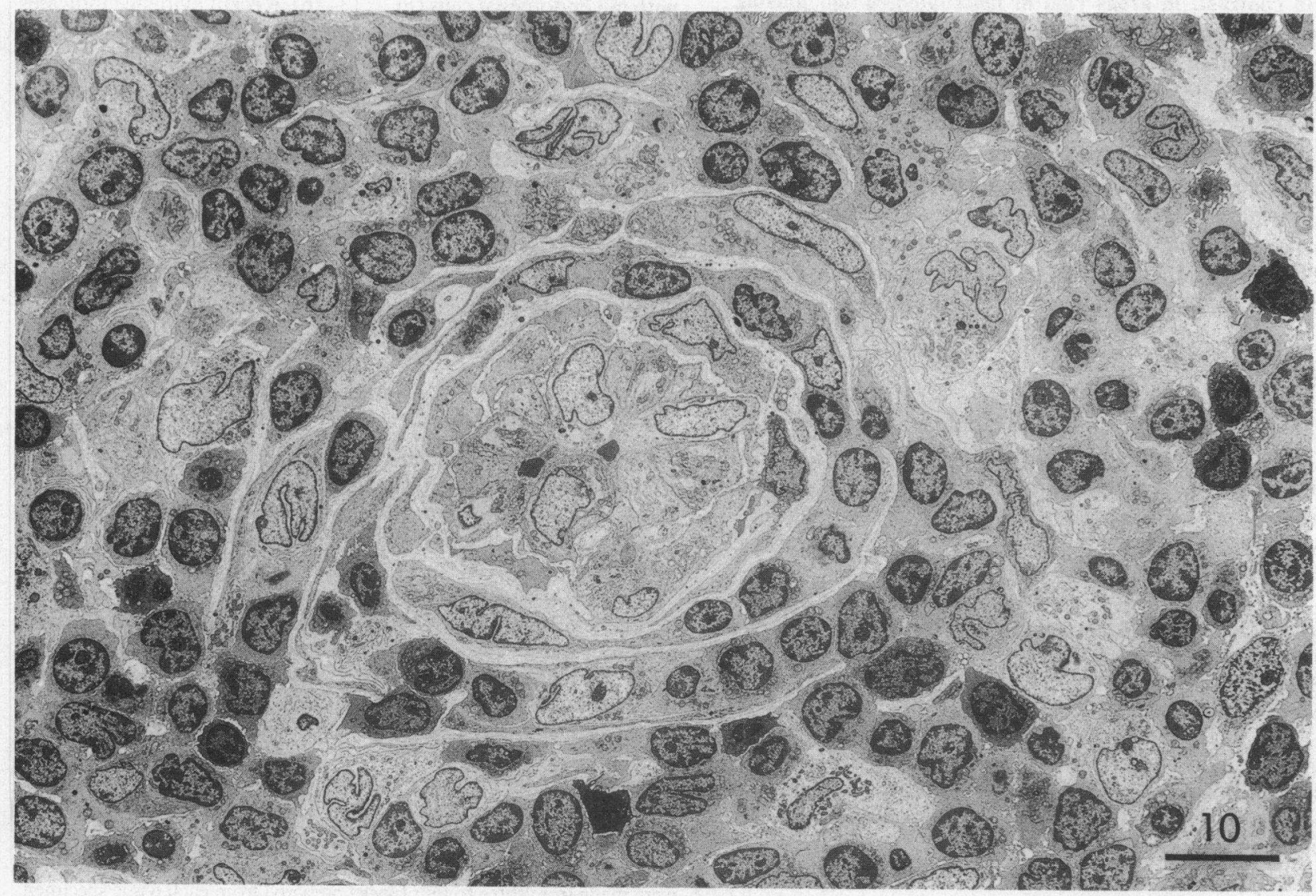

Figure 2. Postcapillary venule in RA synovium lined with tall EC. Numerous perivascular lymphocytes and scattered macrophages, interdigitating cells, and fibroblasts are seen in an area rich in lymphocytes. The vessel has a mildly thickened basement membrane and small lumen. (Original magnification $\times 560$ ). 
height of all of the EC of a given vessel to their mean base (H/B). The mean base was calculated by dividing the circumference of the vessel, measured with a planimeter, by the number of EC counted. The numbers and percentages of lymphocytes, plasma cells, macrophages, and fibroblast(cyte)s within a $30-\mu \mathrm{m}$ range of the vessel were also measured (Fig. $1 B$ ). In addition to areas containing mononuclear cell infiltration, measurements were made in uninfiltrated interstitial areas. The interfollicular areas of the tonsil $(25,26)$ and normal synovium were also examined.

Measurements of vessels were also made using a computer-based morphometric technique $(27,28)$. Employing a custom morphometrics package written in the Department of Pathology, the University of Texas Health Science Center at Dallas, TX, a digitized tablet, interfaced with an Apple II computer, was used for this purpose. In this method, the circumference and total cross-sectional area of postcapillary venules and capillaries and the cross-sectional area of the lining endothelium of these vessels were measured. Partial collapse of vessels as a result of fixation (29) was corrected for by normalization of the cross-sectional area of the vessel and its lumen (28). This was done as follows: a tracing was made of the external circumference of the vessel at the base of the EC. A similar tracing was made of the circumference of the lumen along the luminal surface of the EC. Computerized calculations were then obtained of the total cross-sectional area and luminal area of the vessel normalized in each case to the area of a true circle. The normalization was based on a computerized calculation of the areas of true circles with the measured circumferences. From the total cross-sectional area and the EC area (total area-luminal area), the percent of the cross-sectional area occupied by endothelium was calculated.

Statistical analyses. Correlations between H/B ratio or percent crosssectional area occupied by EC and the percentages and numbers of the inflammatory cell types in the perivascular infiltrates were made by linear regression analysis. Comparisons between the H/B ratios in different areas of the synovium and tonsil tissue were analyzed by one-way analysis of variance, followed by Newman-Keuls multiple comparisons (30) when appropriate.

\section{Results}

In 20 specimens of RA synovial membrane, 153 vessels appearing in the light microscope to be either venules or capillaries, were chosen for examination in the EM. On EM examination, vessels with the appearance of arteries or arterioles and vessels of uncertain identity were excluded. 52 remaining vessels, derived from 20 synovial specimens satisfying criteria for venules or capillaries, were chosen for detailed study. The mean o.d. of these vessels ranged from 5.3 to $50.6 \mu \mathrm{m}$. 24 of these vessels (o.d. $<15 \mu \mathrm{m}$ ) were classified as capillaries and 28 (o.d. 15.2$50.6 \mu \mathrm{m}$ ) were classified as postcapillary venules.

The areas surrounding postcapillary venules (PCV) in RA synovium differed in cellular composition. Of particular interest in this regard was the observation that those PCV that were lined with tall EC were surrounded by infiltrates that contained a high percentage of lymphocytes (Fig. 2). This was especially true when the percentage of lymphocytes was $>50 \%$. In such areas, almost all lymphocytes were small lymphocytes, with a minority of macrophages (3-15\%) and fibroblasts (8-18\%). Some macrophage-like cells in these areas resembled the dendritic cells described in human peripheral blood (31), and mouse lymphoid tissue (32), and the interdigitating cells in rabbit (33) and human

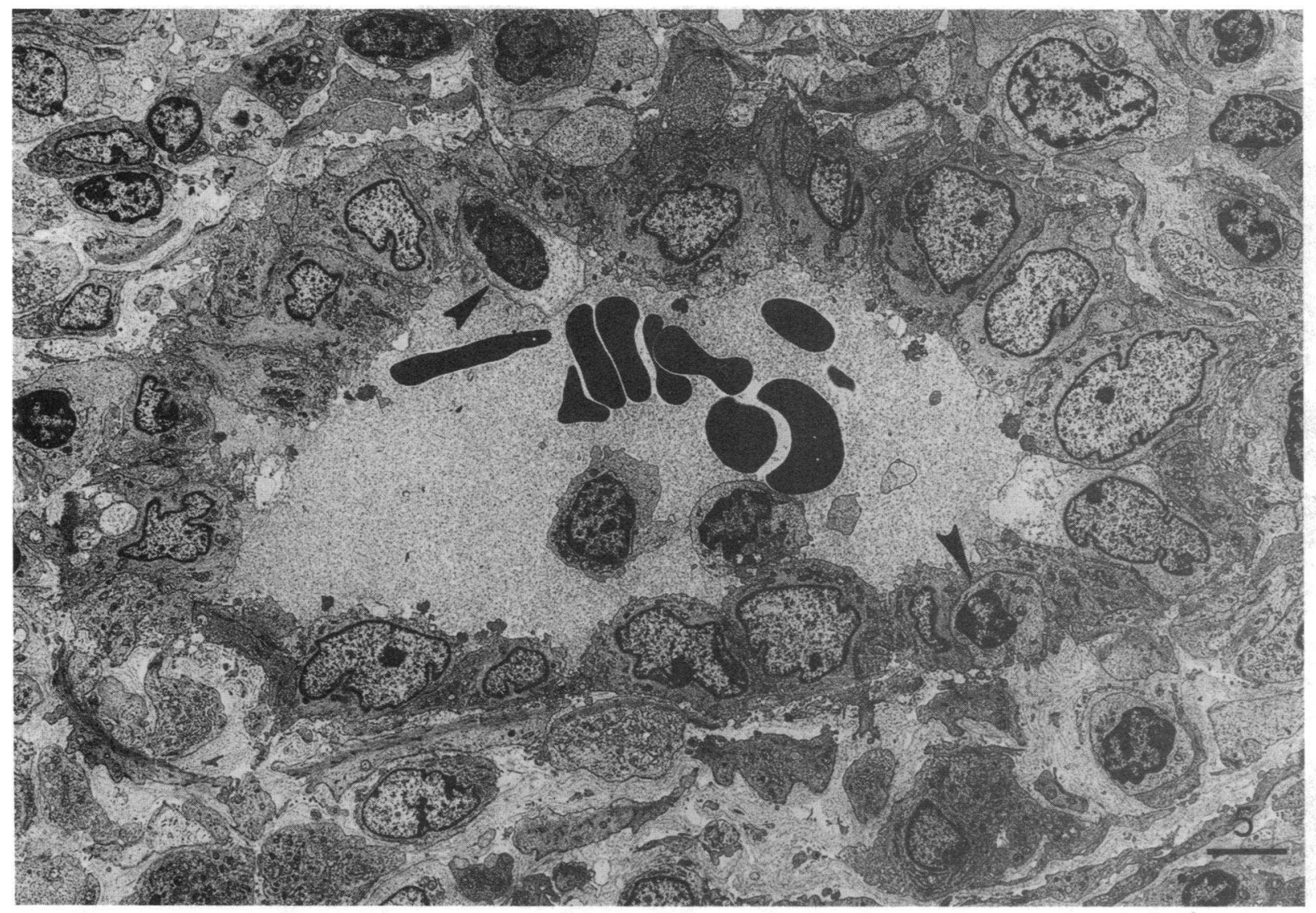

Figure 3. A large postcapillary venule in RA synovium lined with tall endothelium. Two emigrating lymphocytes (arrowheads) are seen. (Original magnification $\times 560$ ). 
lymphoid tissue (34). In smaller PCV, tall EC obstructed the lumens and in these, the basement membrane was somewhat thickened and the inner layers of the surrounding perivascular cells appeared to be tightly linked together (Fig. 2). Passage of lymphocytes through the endothelium was observed only in tall endothelial PCV (Fig. 3). In contrast to the tall EC of PCV surrounded by relatively lymphocyte-rich infiltrates, those in the transitional areas, which were populated largely by macrophages, plasma cells, and lymphocytes, had relatively flat EC (Fig. 4).

Correlations between perivascular mononuclear cell composition and $H / B$ ratios of the $P C V$. The $\mathrm{H} / \mathrm{B}$ ratio of the $\mathrm{PCV}$ in RA synovium showed a strong positive correlation with the percentage of lymphocytes in the chronic mononuclear cell infiltrates within a $30-\mu \mathrm{m}$ range of the vessels $(r=0.94, P<0.001)$ (Fig. 5). In contrast, it showed negative correlations with percent plasma cells $(r=-0.60, P<0.01)$, macrophages $(r=-0.82, P$ $<0.001)$, and fibroblast(cyte)s $(r=-0.58, P<0.01)$. Correlations between the actual numbers of the various mononuclear cell types counted in the same areas and $H / B$ ratios were in the same direction, i.e., for the number of lymphocytes, $r=0.91, P$ $<0.001$; plasma cells, $r=-0.54, P<0.05$; and macrophages, $r=-0.68, P<0.001$.

The perivascular zones of $\mathrm{PCV}$ in noninfiltrated interstitial areas of the RA synovial membrane contained mainly histiocytic cells and fibroblasts $(5,6,35,36)$. In these areas, the percent lymphocytes was usually less than 10 . There was no correlation between the composition of the surrounding cell population and the H/B ratio of the PCV of such areas (data not shown).
Correlation between perivascular mononuclear cell composition and $H / B$ ratios of capillaries. As shown in Fig. 6 , there was no significant correlation between the $\mathrm{H} / \mathrm{B}$ ratio and the composition of the various mononuclear cell populations surrounding the capillaries.

Correlation between mononuclear cell composition and endothelial cell cross-sectional area measured by a computerized morphometric technique. The percent of the PCV cross-sectional area occupied by EC showed a strong positive correlation with the percent lymphocytes in the surrounding infiltrates $(r=0.81$, $P<0.001$ ) (Fig. 7). In contrast, it had significant negative correlations with the percentages of plasma cells $(r=-0.62, P$ $<0.01)$ and macrophages $(r=-0.69, P<0.001)$. These findings indicate that the endothelium of PCV surrounded by lymphocyte-rich populations was not only tall but also occupied a relatively larger fraction of the cross-sectional area of the vessel. There was no significant correlation between EC cross-sectional area and the composition of the mononuclear cell populations surrounding the capillaries (data not shown). It should be emphasized that these results were obtained by a computer-based morphometric method in which correction was made for possible shrinkage of vessels following resection of the tissue or as a result of fixation. They support the previous results obtained by measurement of the $\mathrm{H} / \mathrm{B}$ ratio.

Comparison of endothelial cell height and $H / B$ ratios of $P C V$ in rheumatoid synovium, normal synovium, and tonsil. Mean height and H/B ratios of the EC of PCV were compared in RA synovium, normal synovium, and tonsil (Table I). Perivascular

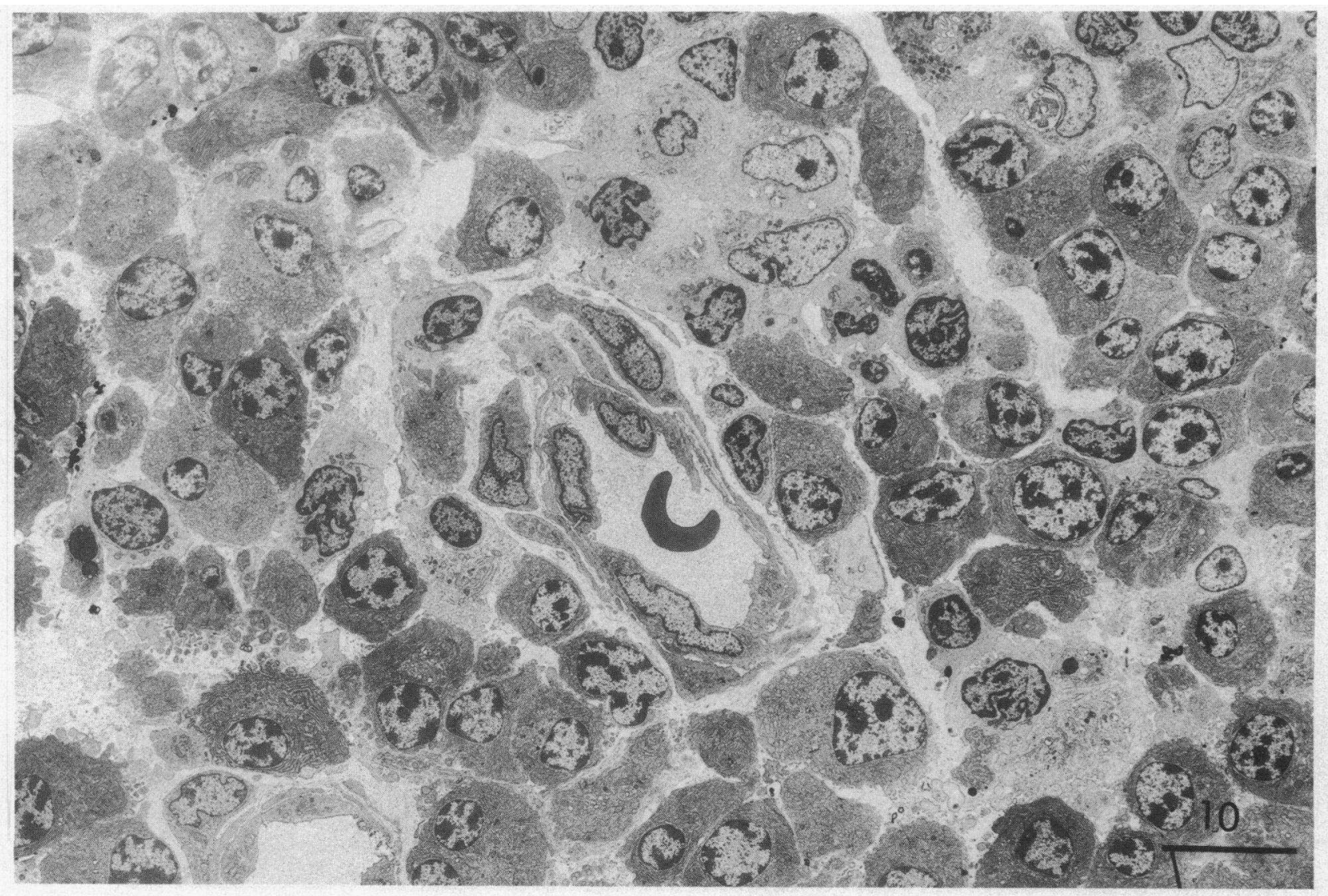

Figure 4. A postcapillary venule in a transitional or antibody-producing area of RA synovium. Many plasma cells and a few lymphocytes and macrophages are observed in the perivascular area. Endothelial cells are flat. (Original magnification $\times 700$ ). 

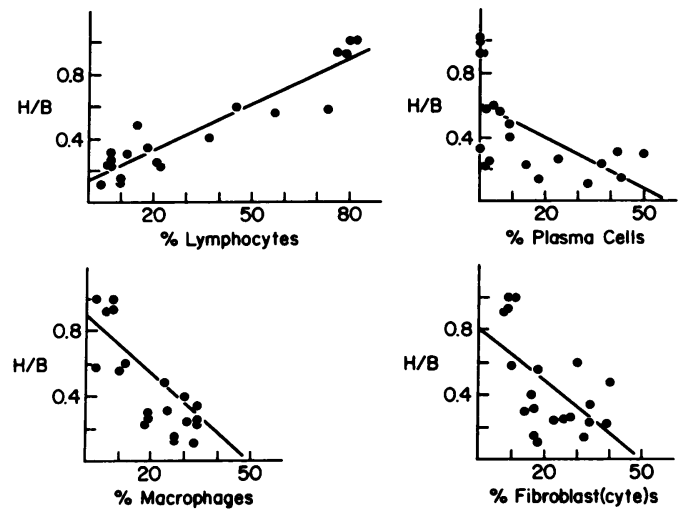

Figure 5. Correlations between percentages of various mononuclear cell types and H/B ratio of EC of postcapillary venules. H/B showed a strong positive correlation with percent lymphocytes $(r=0.94, P$ $<0.001$ ). In contrast, it had negative correlations with the percentage of all other cell types: plasma cells, $r=-0.60, P<0.01$; macrophages, $r=-0.82, P<0.001$; and fibroblasts or fibrocytes, $r=-0.58, P$ $<0.01$.

inflammatory areas of the RA synovium were classified in two subgroups: areas containing $>70 \%$ lymphocytes, and areas containing $<70 \%$ lymphocytes. As shown in Table I, the mean heights of the PCV of the lymphocyte-rich areas of the synovium as well as those of tonsil were significantly greater than those of the lymphocyte-poor areas and noninflammatory interstitial areas of the RA synovium and normal synovium $(P<0.001)$. Similarly, the H/B ratios of the PCV of the lymphocyte-rich areas of the synovium as well as those of the tonsil were also significantly greater than those of the PCV in the other areas $(P$ $<0.001$ ). Mean height and H/B ratios of the EC of capillaries in lymphocyte-rich, lymphocyte-poor, and uninfiltrated areas of the RA synovium were also compared (Table II). Both height and $H / B$ ratios demonstrated no significant differences in these three types of areas.

\section{Discussion}

In previous communications from this laboratory $(1,2,8)$, a distinction has been made between lymphocyte-rich areas of
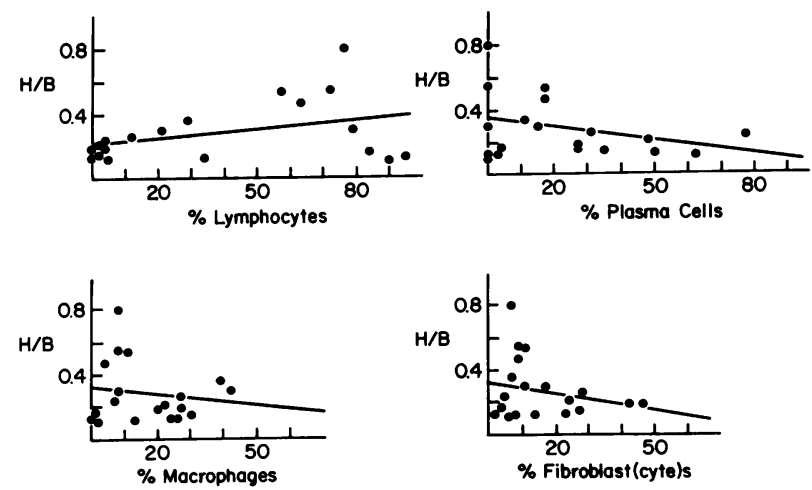

Figure 6. Correlations between percentages of mononuclear cell types and $\mathrm{H} / \mathrm{B}$ ratio of EC of capillaries. $\mathrm{H} / \mathrm{B}$ had no correlation with any of the mononuclear cell types: lymphocytes, $r=0.35$, NS; plasma cells, $r$ $=-0.16$, NS; and fibroblasts or fibrocytes, $r=-0.26$, NS.

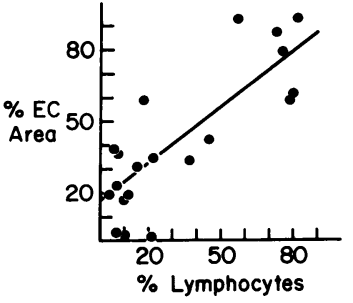

Figure 7. Correlation between percentages of various mononuclear cell types and the fraction of the cross-sectional area of PCV in RA synovium occupied by EC, measured by a computerbased morphometric technique. The percentage of the cross-sectional area occupied by EC showed a strong positive correlation with percent lymphocytes $(r=0.81, P<0.001)$.

RA synovium, containing dense aggregates of lymphocytes, and transitional areas, made up of lymphocytes, macrophages, plasma cells, and small numbers of other cell types. In the present study, the relationship between the "tallness" of the endothelial cells (EC) of the postcapillary venules and capillaries and the composition of the surrounding perivascular infiltrates of RA synovium has been examined. Control studies were carried out with normal synovium and tonsil. It was observed that the "tallness" of the EC of PCV, as measured by their height, $H / B$, and cross-sectional area, showed a clear relationship to the number and percentage of lymphocytes in adjacent mononuclear cell infiltrates. In this respect, the tallness of EC in areas of lymphoid aggregation resembled that of the EC in PCV of the tonsil, which suggests that the mechanism of lymphocyte emigration (13-16) was similar in both tissues. Of additional interest was the occurrence of a clear negative relationship of EC height and tallness (H/B) and percent cross-sectional EC area to the numbers and percentages of macrophages, plasma cells, and fibroblasts in the perivascular infiltrates. In previous work, Freemont et al. (17), observing small blood vessels in the synovial membrane of different arthropathies in the light microscope, found that EC were plump when the numbers of lymphocytes exceeded $150 / \mathrm{mm}^{2}$, and were absent when $<20$ lymphocytes $/ \mathrm{mm}^{2}$ were present. This light microscopic observation suggested that lymphocytes in synovium, as in lymphoid tissue, emigrated from tall endothelial PCV. Our findings in the EM have extended this observation by demonstrating that $(a)$ the tall endothelial vessels surrounded by lymphocyte-rich infiltrates in synovium are PCV, $(b)$ there is a high correlation between the tallness and size of the EC and the number and percent of lymphocytes in the perivascular infiltrate, $(c)$ PCV in transitional areas, containing a variety of mononuclear cells, and in uninfiltrated interstitial areas tend to have flat endothelium, and $(d)$ capillaries in all of these areas also have flat endothelium. Taken together, our findings indicate that the PCV of the RA synovial membrane, from which lym-

Table I. Height and $H / B$ of EC of PCV*

\begin{tabular}{|c|c|c|c|c|}
\hline PCV & $\begin{array}{l}\text { No. } \\
\text { of vessels }\end{array}$ & Mean o.d. & $\begin{array}{l}\text { Height } \neq \text { of } \\
\text { EC }\end{array}$ & $\mathrm{H} / \mathrm{B} \ddagger$ of $\mathrm{EC}$ \\
\hline & & $\mu m$ & $\mu m$ & \\
\hline \multicolumn{5}{|l|}{$\begin{array}{l}\text { Rheumatoid synovium } \\
\text { inflammatory areas }\end{array}$} \\
\hline$>70 \%$ Lymphocytes & 5 & $27.0 \pm 14.0 \S$ & $6.94 \pm 1.30^{1}$ & $0.89 \pm 0.18^{a}$ \\
\hline$<70 \%$ Lymphocytes & 15 & $28.8 \pm 12.0$ & $3.94 \pm 1.45^{2}$ & $0.32 \pm 0.15^{b}$ \\
\hline Noninflammatory areas & 8 & $27.3 \pm 12.8$ & $3.09 \pm 0.92^{3}$ & $0.32 \pm 0.11^{\mathrm{c}}$ \\
\hline Tonsil & 13 & $27.8 \pm 8.82$ & $7.15 \pm 1.88^{4}$ & $0.72 \pm 0.20^{d}$ \\
\hline Normal synovium & 10 & $21.6 \pm 7.41$ & $2.86 \pm 1.48^{5}$ & $0.30 \pm 0.12^{e}$ \\
\hline
\end{tabular}

* Mean o.d., 15.2-50.6 $\mu \mathrm{m}$.

$\ddagger 1$ or 4 vs. 2,3 , or $5, P<0.001$; a or d vs. b, c, or e, $P<0.001$.

$\S$ Mean \pm SD. 
Table II. Height and H/B of EC of Capillaries*

\begin{tabular}{|c|c|c|c|c|}
\hline Capillary & $\begin{array}{l}\text { No. } \\
\text { of vessels }\end{array}$ & Mean o.d. & $\begin{array}{l}\text { Height } \ddagger \text { of } \\
\text { EC }\end{array}$ & $\begin{array}{l}\mathrm{H} / \mathrm{B} \ddagger \text { of } \\
\mathrm{EC}\end{array}$ \\
\hline & & $\mu m$ & $\mu m$ & \\
\hline \multicolumn{5}{|l|}{$\begin{array}{l}\text { Rheumatoid synovium } \\
\text { inflammatory areas }\end{array}$} \\
\hline$>70 \%$ Lymphocytes & 6 & $9.03 \pm 3.07 \S$ & $2.54 \pm 1.71$ & $0.34 \pm 0.28$ \\
\hline$<70 \%$ Lymphocytes & 13 & $10.7 \pm 2.80$ & $2.17 \pm 0.67$ & $0.25 \pm 0.13$ \\
\hline Noninflammatory areas & 5 & $11.3 \pm 1.75$ & $2.10 \pm 1.07$ & $0.27 \pm 0.17$ \\
\hline
\end{tabular}

* Mean o.d. $<15 \mu \mathrm{m}$

$\ddagger$ Differences not significant.

$\S$ Mean \pm SD.

phocytes emigrate to form perivascular lymphoid aggregates, resemble those of lymphoid tissue.

What are the factors that determine the observed relationship between perivascular lymphocyte concentration and EC tallness? Graham et al. (37), studying a peroxidase-induced synovitis in the rabbit, suggested that plump EC developed in inflammatory foci before the appearance of dense lymphoid aggregates. It is of interest, in this regard, that rats immunized with spinal cord or myelin basic protein developed Ia-positive EC before the development of the inflammatory infiltrates of experimental allergic encephalomyelitis (38). These observations suggest that the development of tall EC may be a consequence of subtle early inflammatory events that occur before the emigration of mononuclear cells.

The emigration of lymphocytes involves several steps. In the first of these, the circulating lymphocyte binds to the EC of a postcapillary venule (39); a specific ligand on the lymphocyte and receptor on the EC appear to be involved. After binding, the lymphocyte traverses the endothelium and migrates to an appropriate microenvironment. It has been shown in this laboratory that interleukin 1 (IL-1) increases the binding of human B and T lymphocytes to endothelial cell monolayers (40). IL-1 has also been shown to be a chemotactic agent for lymphocytes (41), so that in addition to stimulating EC binding, it may attract the lymphocyte through the endothelium to its appropriate place in the extracellular microenvironment. In view of recent observations $(5,35,36)$ that uninfiltrated areas of RA synovium contain large numbers of Ia-positive, macrophage-positive histiocytic cells, which may be able to secrete IL-1, it is possible that the uninfiltrated synovium may be prepared to support lymphocyte emigration, after an appropriate initiating event, by virtue of the EC stimulating and chemotactic actions of IL- 1 .

The possibility that lymphocytes may play a role in the stimulation of EC size must also be considered. Flattening of tall endothelium in mouse lymph node after thymectomy (42) and reappearance of tall $\mathrm{EC}$ after transfusion of syngeneic thoracic duct lymphocytes (43) have been observed. Induction of Ia expression (44) and increased binding of lymphocytes on EC (45) by supernatants of activated $T$ cells or interferon- $\gamma$ also suggest an active function on the part of lymphocytes in their interaction with EC. In addition, the recent observation that IL1 and interferon- $\gamma$ have a synergistic effect in modifying the phenotypic expression of EC (46) raises the possibility that there is a combined effect of macrophages and lymphocytes in stimulating the development of tall endothelium. This could be an early event in the development of RA synovitis.

\section{Acknowledgments}

The authors wish to thank Dr. Kazushi Hirohata and Dr. Hitoshi Ishikawa (Kobe University, Japan) for their help in obtaining synovial specimens, and Dr. H. K. Hagler and Dr. M. Buja for allowing us to use their computer-based morphometric apparatus.

This work was supported by National Institutes of Health grant AM09989, National Institutes of Health Research Career Award AM14155, and an Arthritis Foundation Clinical Research Center Grant.

\section{References}

1. Kobayashi, I., and M. Ziff. 1973. Electron microscopic studies of lymphoid cells in the rheumatoid synovial membrane. Arthritis Rheum. 16:471-486.

2. Ishikawa, H., and M. Ziff. 1976. Electron microscopic observations of immunoreactive cells in the rheumatoid synovial membrane. Arthritis Rheum. 19:1-14.

3. Janossy, G., O. Duke, L. W. Poulter, G. Panayi, M. Bofill, and G. Goldstein. 1981. Rheumatoid arthritis: a disease of T-lymphocyte/ macrophage immunoregulation. Lancet. ii:839-842.

4. Klareskog, L., U. Forsum, A. Wigren, and H. Wigzell. 1982. Relationships between HLA-DR-expressing cells and T lymphocytes of different subsets in rheumatoid synovial tissue. Scand. J. Immunol. 15: 501-507.

5. Burmester, G. R., P. Locher, B. Koch, R. J. Winchester, A. Dimitriu-Bona, J. R. Kalden, and W. Mohr. 1983. The tissue architecture of synovial membranes in inflammatory and non-inflammatory joint diseases. Rheumatol. Int. 3:173-181.

6. Young, C. L., T. C. Adamson, J. H. Vaughan, and R. I. Fox. 1984. Immunohistologic characterization of synovial membrane lymphocytes in rheumatoid arthritis. Arthritis Rheum. 27:32-39.

7. Meijer, C. J. L. M., C. B. de Graaff-Reitsma, G. J. M. Lafeber, and A. Cats. 1982. In situ localization of lymphocyte subsets in synovial membranes of patients with rheumatoid arthritis with monoclonal antibodies. J. Rheumatol. 9:359-365.

8. Kurosaka, M., and M. Ziff. 1983. Immunoelectron microscopic study of the distribution of $\mathrm{T}$ cell subsets in rheumatoid synovium. $J$. Exp. Med. 158:1191-1210.

9. Poppema, S., A. K. Bhan, E. L. Reinherz, R. T. McCluskey, and S. F. Schlossman. 1981. Distribution of T cell subsets in human lymph nodes. J. Exp. Med. 153:30-41.

10. Van Voorhis, W. C., R. M. Steinman, L. S. Hair, J. Luban, M. D. Witmer, S. Koide, and Z. A. Cohn. 1983. Specific antimononuclear phagocyte monoclonal antibodies. Application to the purification of dendritic cells and the tissue localization of macrophages. J. Exp. Med. 158:126-145.

11. Janossy, G., N. Tidman, W. S. Selby, J. A. Thomas, S. Granger, P. C. Kung, and G. Goldstein. 1980. Human T lymphocytes of inducer and suppressor type occupy different microenvironments. Nature (Lond.). 288:81-84

12. Smiley, J. D., C. Sachs, and M. Ziff. 1968. In vitro synthesis of immunoglobulin by rheumatoid synovial membrane. J. Clin. Invest. 47 : 624-632.

13. Gowans, J. L., and E. J. Knight. 1964. The route of recirculation of lymphocytes in the rat. Proc. R. Soc. Lond. (Biol.) 159:257-282.

14. Marchesi, V. T., and J. L. Gowans. 1964. The migration of lymphocytes through the endothelium of venules in lymph nodes: an electron microscope study. Proc. R. Soc. Lond. B Biol. Sci. 159:283-290.

15. Schoefl, G. I. 1972. The migration of lymphocytes across the vascular endothelium in lymphoid tissue. J. Exp. Med. 136:568-588.

16. Anderson, A. O., and N. D. Anderson. 1976. Lymphocyte emigration from high endothelial venules in rat lymph nodes. Immunology. 31:731-748.

17. Freemont, A. J., C. J. P. Jones, M. Bromley, and P. Andrews. 1983. Changes in vascular endothelium related to lymphocyte collections in diseased synovia. Arthritis Rheum. 26:1427-1433. 
18. Espinoza, L. R., F. B. Vasey, C. G. Espinoza, T. S. Bocanegra, and B. F. Germain. 1982. Vascular changes in psoriatic synovium. A light and electron microscopic study. Arthritis Rheum. 25:677-684.

19. Norton, W. L., D. Lewis, and M. Ziff. 1966. Light and electron microscopic observations on the synovitis of Reiter's disease. Arthritis Rheum. 9:747-757.

20. Sheehan, D. C., and B. B. Hrapchak. 1980. Theory and Practice of Histotechnology. 2nd ed. C. V. Mosby Co., St. Louis, MO. 40-58.

21. Weiss; L., and R. O. Greep. 1977. Histology. 4th ed. McGrawHill, Inc., New York. 378-420.

22. Rhodin, J. A. G. 1968. Ultrastructure of mammalian venous capillaries, venules and small collecting veins. J. Ultrastruct. Res. 25: 452-500.

23. Fernando, N. V. P., and H. Z. Movat. 1964. The fine structure of the terminal vascular bed. III. The capillaries. Exp. Mol. Pathol. 3: 87-97.

24. Movat, H. Z., and N. V. P. Fernando. 1964. The fine structure of the terminal vascular bed. IV. The venules and their perivascular cells. Exp. Mol. Pathol. 3:98-114.

25. Si, L., G. Roscoe, and T. L. Whiteside. 1983. Selective distribution and quantitation of T-lymphocyte subsets in germinal centers of human tonsils. Arch. Pathol. Lab. Med. 107:228-231.

26. McMillan, E. M., R. Wasik, and M. A. Everett. 1981. Identification of T-lymphocytes and T-subsets in human tonsil using monoclonal antibodies and the immunoperoxidase technic. Am. J. Clin. Pathol. 76: 737-744.

27. Muntz, K. H., H. K. Hagler, H. J. Boulas, and L. M. Buja. 1984. Fluorescence microscopic morphometry of functioning blood vessels and adrenergic nerves in myocardium. Anat. Rec. 208:65-68.

28. Willerson, J. T., L. D. Hillis, and L. M. Buja. 1982. Ischemic Heart Disease. Clinical and Pathophysiological Aspects. Raven Press, New York. 7-83.

29. Belisle, C., and G. Sainte-Marie. 1985. The narrowing of high endothelial venules of the rat lymph node. Anat. Rec. 211:184-191.

30. Zar, J. H. 1984. Biostatistical Analysis. 2nd ed. Prentice-Hall, Inc., Englewood Cliffs, N.J. 190-191.

31. Van Voorhis, W. C., L. S. Hair, R. M. Steinman, and G. Kaplan. 1982. Human dendritic cells. Enrichment and characterization from peripheral blood. J. Exp. Med. 155:1172-1187.

32. Steinman, R. M., G. Kaplan, M. D. Witmer, and Z. A. Cohn. 1979. Identification of a novel cell type in peripheral lymphoid organs of mice. V. Purification of spleen dendritic cells, new surface markers, and maintenance in vitro. J. Exp. Med. 149:1-16.

33. Veldman, J. E., and E. Kaiserling. 1980. Interdigitating Cells,
The Reticuloendothelial System. Vol. 1, Morphology. Eds: I. Carr, W. T. Daems. Plenum Publishing Corp., New York. 381-416.

34. Heusermann, U., H. J. Stutte, and H. K. Muller-Hermelink. 1974. Interdigitating cells in the white pulp of the human spleen. Cell Tissue Res. 153:415-417.

35. Winchester, R. J., and G. R. Burmester. 1981. Demonstration of Ia antigens on certain dendritic cells and on a novel elongated cell found in human synovial tissue. Scand. J. Immunol. 14:439-443.

36. Iguchi, T., M. Kurosaka, and M. Ziff. 1984. Electron microscopic study of HLA-DR staining cells in the rheumatoid synovial membrane. Arthritis Rheum. 27:S72.

37. Graham, R. C., and S. L. Shannon. 1972. Peroxidase arthritis. II. Lymphoid cell-endothelial interactions during a developing immunologic inflammatory response. Am. J. Pathol. 69:7-24.

38. Sobel, R. A., B. W. Blanchette, A. K. Bhan, and R. B. Colvin. 1984. The immunopathology of experimental allergic encephalomyelitis. I. Quantitative analysis of inflammatory cells in situ. J. Immunol. 132: 2393-2407.

39. Stamper, H. B., and J. J. Woodruff. 1976. Lymphocyte homing into lymph nodes: in vitro demonstration of the selective affinity of recirculating lymphocytes for high-endothelial venules. J. Exp. Med. 144: 828-833.

40. Cavender, D. E., D. O. Haskard, B. Joseph, and M. Ziff. 1986. Interleukin 1 increases the binding of human $B$ and $T$ lymphocytes to endothelial cell monolayers. J. Immunol. 136:203-207.

41. Miossec, P., and M. Ziff. 1984. Lymphocyte chemotactic activity of human interleukin 1. J. Immunol. 133:2007-2011.

42. Parrott, D. M. V., M. A. B. de Sousa, and J. East. 1966. Thymusdependent areas in the lymphoid organs of neonatally thymectomized mice. J. Exp. Med. 123:191-204.

43. Goldschneider, I., and D. D. McGregor. 1968. Migration of lymphocytes and thymocytes in the rat. I. The route of migration from blood to spleen and lymph nodes. J. Exp. Med. 127:155-168.

44. Pober, J. S., M. A. Gimbrone, R. S. Cotran, C. S. Reiss, S. J. Burakoff, W. Fiers, and K. A. Ault. 1983. Ia expression by vascular endothelium is inducible by activated $\mathrm{T}$ cells and by human interferon. J. Exp. Med. 157:1339-1353.

45. Yu, C.-L., D. O. Haskard, D. E. Cavender, A. R. Johnson, and M. Ziff. 1985. Human gamma interferon increases the binding of $T$ lymphocytes to endothelial cells. Clin. Exp. Immunol. In press.

46. Montesano, R., L. Orci, and P. Vassali. 1985. Human endothelial cell cultures: phenotypic modulation by leukocyte interleukins. J. Cell. Physiol. 122:424-434. 